\title{
Psychometric Comparison of the Performance of Quality of Life Assessment Instruments in Dermatology-the DLQI, Skindex-16, and Skindex-17 -in a Brazilian Population.
}

\section{Marilia Formentini Scotton Jorge ( $\sim$ marilia_scotton@yahoo.com.br )}

Universidade Estadual Paulista Julio de Mesquita Filho Faculdade de Medicina Campus de Botucatu https://orcid.org/0000-0003-1667-5160

loana Bittencourt Mourão

Universidade Estadual Paulista Julio de Mesquita Filho Faculdade de Medicina Campus de Botucatu

Ticiane Dionisio Sousa

Universidade Estadual Paulista Julio de Mesquita Filho Faculdade de Medicina Campus de Botucatu

Camila Fernandes Pollo

Universidade Estadual Paulista Julio de Mesquita Filho Faculdade de Medicina Campus de Botucatu

Silmara Meneguin

Universidade Estadual Paulista Julio de Mesquita Filho Faculdade de Medicina Campus de Botucatu

Hélio Amante Miot

Universidade Estadual Paulista Julio de Mesquita Filho Faculdade de Medicina Campus de Botucatu

\section{Research}

Keywords: DLQI (Dermatology Life Quality Index), Psychometric comparison, quality of life assessment instruments, Skindex-16, Skindex-17, Brazilian population

Posted Date: June 29th, 2021

DOI: https://doi.org/10.21203/rs.3.rs-656859/v1

License: (c) (i) This work is licensed under a Creative Commons Attribution 4.0 International License.

Read Full License 


\section{Abstract}

Background: The DLQI (Dermatology Life Quality Index) is the most commonly used instrument for evaluating the quality of life in dermatology. Skindex was developed as a multidimensional instrument with successive versions published, the most recent being Skindex-16 and Skindex-17, both derived from Skindex-29 through different techniques. This study aimed to compare the three instruments-the DLQI, Skindex-16, and Skindex-17-according to their psychometric performance to refine the assessment of the quality of life among dermatological patients.

Methods: A methodological study compared the psychometric performance of the DLQI, Skindex-16 (Sk16), and Skindex-17 (Sk-17) instruments among adults with dermatoses that were classified according to characteristic physical symptoms and psychological or social domains. Analyses were performed to assess internal consistency, correlation, test-retest reproducibility, and responsiveness according to classical psychometry and to test discrimination and difficulty according to the item response theory.

Results: The sample consisted of 229 patients predominantly women $(71 \%)$ of adult age (average 45 years) and intermediate phototypes (III and IV $=73 \%$ ). The analyses of internal consistency for the instruments resulted in Cronbach-a coefficients $>0.80$. There was adequate test-retest reproducibility and responsiveness for all dimensions of the instruments. The IRT (Iten Response Theory) analysis indicated adequate ordering and discrimination ( $a>1.0$ ) for all items of the DLQI, Sk-16, and Sk-17; four items of Sk16 did not adequately adhere to the TRI model $(p<0.01)$. The items with the greatest discrimination were q3 (domestic activities) and q5 (leisure activities) in the DLQl; F2 (desire to be with people) and E6 (annoyance) in Sk-16; and S4 (irritated skin), P5 (relationship), and P6 (autonomy of tasks) in Sk-17. The Sk-16 and Sk-17 instruments presented more items that registered mild impacts on the quality of life (b $<-0.5)$.

Conclusions: The DLQI, Sk-16, and Sk-17 presented adequate psychometric performance for the assessment of health-related quality of life in a Brazilian sample. The multidimensional instruments (Sk16 and Sk-17) were more sensitive to mild impacts on quality of life.

\section{Introduction}

Quality of life assessment instruments can provide more personalized information than traditional clinical data on the impact of health conditions on patients' lives. (1) Metrics based on the perspective of patients (patient-centered outcomes) are important for monitoring chronic diseases. Such an assessment is based on the patient's opinion without interference or interpretations by the doctor, contributing to the understanding of the health-disease process as well as the evaluation of treatments.

The first well-structured generic instrument for evaluating health-related quality of life (HRQOL) in dermatology was the Dermatology Life Quality Index (DLQI), published in 1994 (2) and validated for Portuguese (DLQI-BRA) in 2004. (3) It is a one-dimensional instrument, composed of 10 items arranged in six categories (symptoms, daily activity, work/school, leisure, interpersonal relationships, and treatment), 
that assesses the individual's perception in the last week. (4) There are five possible answers for each item (very much, a lot, a little, not at all, and not relevant); the score for each item ranges from 0 to 3 . (25) Conventionally, DLQI scores are interpreted based on the algebraic sum of the indexes of the 10 items evaluated: without compromising quality of life $(0-1)$, with mild (2-5), moderate (6-10), severe (11-20), or very severe (21-30) impairment. (6)

The DLQI is the most frequently used instrument for clinical follow-up and treatment guidelines (7-9); however, in recent years, its dimensionality and psychometric properties, such as the ordering of item scores and presence of differential functioning of the items, have been questioned in consideration of the item response theory (IRT). (10-14)

In 1996, Chren et al. developed the first version of Skindex, a multidimensional instrument for evaluating HRQOL among patients with dermatological diseases, with 61 items aimed to assess several psychological and psychosocial aspects not yet addressed. (15) The second version of the instrument, Skindex-29, was published the following year, in 1997. (16) In 2000, the third version of the instrument was published: Skindex-16 (Sk-16). In this new version, the effects of dermatoses on HRQOL were divided into three domains: symptoms, emotions, and functioning The items assess the frequency of discomfort experienced through a seven point Likert scale (ranging from never bothered to always bothered). (17) Each item is transformed into a score that ranges from 0 (without discomfort) to 100 (maximum discomfort).

In 2006, a new version was published; Skindex-17 (Sk-17) is based on the IRT and not on the classic test theory, like the other versions. Sk-17 has two subscales: psychosocial and symptoms. On the psychosocial subscale, the scores range from 1 to 24 and are classified according to the impact on HRQOL: less than five (little), between five and nine (moderate), and greater than nine (high). The symptom scale result is dichotomized; there are five response options (never, rarely, sometimes, often, and all the time), and scores greater than or equal to five indicate that many symptoms are present. (18, 19)

The development of the Sk-16 and Sk-17 instruments differed, and the two instruments vary in terms of structure, dimensionality, and scores. Despite coincident items, the overall designs of the instruments are different. They have not yet been compared in terms of their psychometric properties.

By comparing the available instruments, it is possible to better understand the sensitivity of HRQOL assessment tools. This study aimed to compare the psychometric performance of the DLQI-BRA, Sk-16, and Sk-17 in a Brazilian population.

\section{Methods}

A methodological study was conducted to compare psychometric performance between HRQOL instruments. The project was approved by the institutional ethics committee (no. 2,367,912), and all participants signed a consent form before inclusion. 
Adult patients from the Hospital das Clínicas, Faculty of Medicine of Botucatu-Unesp with dermatological diseases, between December 2017 and October 2019, were included. During a medical consultation, demographic information about the dermatological disease was collected, and the patient was asked to complete Sk-16, the DLQI-BRA, and Sk-17 (in that order). The underlying dermatoses were classified into three groups by consensus among the dermatologist authors: evident psychosocial impact (e.g. vitiligo, melasma), predominantly symptomatic impact (e.g. venous ulcer, urticaria), or symptomatic and psychosocial impact (e.g. psoriasis, hidradenitis suppurativa).

The frequency of responses for each item of the instruments was evaluated, and the "ground" effect was assessed (frequency of responses $>50 \%$ for minimum response).

The internal consistency of each dimension of the instruments (Sk-17, Sk-16, DLQI-BRA) was assessed by Cronbach's alpha coefficient with a $95 \% \mathrm{Cl}$, whose lower interval should exceed 0.8 in constructs of adequate consistency. (20)

The correlations between the questionnaire scores were assessed using Spearman's linear correlation coefficients, which should be greater than 0.7 (strong correlation). (21)

The test-retest reliability was assessed in a subgroup of 21 subjects with no clinical alteration of their dermatoses, with an interval of 7-30 days between the interviews. The test-retest reproducibility was analyzed by the intraclass correlation index (ICC) for single measures (complete agreement) and considered adequate if greater than 0.8. (22)

For responsiveness analysis, the response to treatment was evaluated within a subgroup of 21 patients who presented clinical alteration of their dermatosis through the Wilcoxon test, considered adequate if $p$ $<0.05$.

Data were collected to assess temporal stability and responsiveness through convenience sampling among patients with brief outpatient returns (within 7-30 days). The presence or absence of clinical alteration was assessed by the attending dermatologist and inquired of the patient. All evaluations were consistent between the patients and attending physicians.

The instruments were evaluated for global informativeness (information function) and the characteristics of the items (a: discrimination; b: difficulty) according to the multidimensional IRT. (23) For model adjustments, we used the representation identified by the Akaike information criterion (AIC) and Bayesian information criterion (BIC). The adjustment of the items to the model was performed using the S2-X2 statistic, considered appropriate if $p \geq 0.01$.

Assuming the need for up to 10 participants per item in each instrument, a minimum of 170 participants was estimated for the comparison of the instruments. $(24,25)$

The data were tabulated in Microsoft Excel and analyzed using IBM SPSS 25.0 software, JASP 0.14, and $\mathrm{R}$ (mIRT package). (23) 


\section{Results}

In total, 229 participants were interviewed, resulting in 271 complete questionnaires (including test-retest and responsiveness). The clinical demographic characteristics are listed in Table 1. The patients were predominantly married, female, of adult age with intermediate phototypes. 
Table 1

Clinical demographic characteristics and quality of life for the 229 patients included in the study.

\begin{tabular}{|c|c|c|}
\hline & & Value \\
\hline Age (years)a & & $45(15)$ \\
\hline \multirow[t]{2}{*}{ Sex - n (\%) } & Female & $163(71)$ \\
\hline & Male & $66(29)$ \\
\hline \multirow[t]{6}{*}{ Phototype - n (\%) } & I & $4(2)$ \\
\hline & II & $48(21)$ \\
\hline & III & $120(52)$ \\
\hline & IV & $47(21)$ \\
\hline & V & $8(4)$ \\
\hline & VI & $2(1)$ \\
\hline \multirow[t]{3}{*}{ Marital status - n (\%) } & Single & $64(28)$ \\
\hline & Married & $127(55)$ \\
\hline & Divorced/Widower & $38(17)$ \\
\hline \multirow[t]{3}{*}{ Educational level - n (\%) } & Elementary & $71(31)$ \\
\hline & High School & $63(28)$ \\
\hline & College & $95(41)$ \\
\hline \multirow[t]{4}{*}{ Family income - n (\%) } & Up to a minimum wage & $29(13)$ \\
\hline & Between 1 and 3 minimum wages & $88(38)$ \\
\hline & Between 1 and 3 minimum wages & $51(22)$ \\
\hline & More than 5 minimum wages & $61(27)$ \\
\hline \multirow[t]{3}{*}{ Classification of dermatosis - $\mathrm{n}(\%)$} & Physical/Symptomatic & $57(25)$ \\
\hline & Psychological/Social & $87(38)$ \\
\hline & Both & $85(37)$ \\
\hline Dermatose duration (years)a & & $6(2-14)$ \\
\hline DLQIb & & $5(2-10)$ \\
\hline \multicolumn{3}{|l|}{ Sk-16b } \\
\hline Symptoms & & $29(8-58)$ \\
\hline
\end{tabular}




\begin{tabular}{|lc|}
\hline & Value \\
\hline Emoctions & $62(31-86)$ \\
\hline Functioning & $23(3-53)$ \\
\hline Sk-17b & \\
\hline Symptom & $5(2-10)$ \\
\hline Psychosocial & $4(1-10)$ \\
\hline
\end{tabular}

The dermatoses included in the study are presented in Table 2. 
Table 2

List of diagnostic groups and classification regarding physical/symptomatic and psychological/social dimensions of the sampled patients $(n=229)$.

\begin{tabular}{|c|c|c|c|}
\hline Diagnose & Classification & $\mathrm{n}$ & $\%$ \\
\hline Acne & Psychological/social & 17 & 7,4 \\
\hline Alopecias & Psychological/social & 12 & 5,2 \\
\hline Annular Granuloma & Psychological/social & 1 & 0,4 \\
\hline Benign tumors & Psychological/social & 4 & 1,7 \\
\hline Bullous disorders & Physical/symptomatic + Psychological/social & 16 & 7,0 \\
\hline Chronic ulcers & Physical/symptomatic & 11 & 4,8 \\
\hline Collagenoses & Physical/symptomatic + Psychological/social & 10 & 4,4 \\
\hline Drug eruption & Physical/symptomatic & 4 & 1,7 \\
\hline Eczema & Physical/symptomatic + Psychological/social & 19 & 8,3 \\
\hline Hidradenitis suppurativa & Physical/symptomatic + Psychological/social & 3 & 1,3 \\
\hline Infectious dermatoses & Physical/symptomatic & 19 & 8,3 \\
\hline Keloid cicatrix & Psychological/social & 1 & 0,4 \\
\hline Malignant tumors & Psychological/social & 5 & 2,2 \\
\hline Melasma & Psychological/social & 29 & 12,7 \\
\hline Photoaging & Psychological/social & 7 & 3,1 \\
\hline Pityriasis rosea & Physical/symptomatic & 2 & 0,9 \\
\hline Psoriasis & Physical/symptomatic + Psychological/social & 55 & 24,1 \\
\hline Rosacea & Psychological/social & 8 & 3,5 \\
\hline Urticaria & Physical/symptomatic & 2 & 0,9 \\
\hline Vitiligo & Psychological/social & 4 & 1,7 \\
\hline
\end{tabular}

The analysis of internal consistency for the three instruments resulted in Cronbach's alpha coefficients with indexes $\geq 0.80$ (Table 3 ). 
Table 3

Cronbach's alpha coefficients $(95 \% \mathrm{Cl})$ for the Skindex-16, Skindex-17, and DLQI-BRA instruments $(n=229)$.

\begin{tabular}{|llll|}
\hline Instrument & Dimension & Cronbach's alpha & Cl 95\% \\
\hline DLQI-BRA & - & 0,84 & $0,80-0,87$ \\
Skindex-16 & Symptoms & 0,86 & $0,82-0,88$ \\
& Emoctions & 0,92 & $0,91-0,94$ \\
& Functioning & 0,86 & $0,83-0,89$ \\
Skindex-17 & Symptoms & 0,81 & $0,77-0,84$ \\
& Psychosocial & 0,93 & $0,91-0,94$ \\
\hline
\end{tabular}

The scores of the instruments (Table 4) indicated a correlation (rho) with each other; however, the correlation between the dimensions of Sk-17 was greater than between the dimensions of Sk-16. The DLQI-BRA indicated a moderate to strong correlation with all other dimensions (rho $\geq 0.59$ ), with a more consistent correlation with the dimensions of Sk-17.

Table 4

Correlation coefficients (Spearman's rho) between the Skindex-16, Skindex-17, and DLQI-BRA instruments for the discomfort caused by the disease $(n=229)$. All correlations resulted in $p<0.01$.

\begin{tabular}{|llllll|}
\hline & Sk-16S & Sk-16E & Sk-16F & Sk-17S & Sk-17PS \\
\hline Sk-16E & 0,44 & & & & \\
\hline Sk-16F & 0,72 & 0,35 & & & \\
\hline Sk-17S & 0,48 & 0,73 & 0,41 & 0,94 & 0,75 \\
\hline Sk-17PS & 0,46 & 0,71 & 0,47 & 0,76 & \\
\hline DLQI & 0,60 & 0,63 & 0,59 & \\
\hline $\begin{array}{l}\text { Sk-16-: Symptoms dimension of Sk-16; Sk-16E: Emoctions dimension of Sk-16; Sk-16F: Functioning } \\
\text { dimension of Sk-16; Sk-17S: Symptoms dimension Sk-17; Sk-17PS: Psychosocial dimension of Sk-17. }\end{array}$
\end{tabular}

There were no major difficulties in interpreting and responding to the items; however, due to the coincident items in the Sk-16 and Sk-17 questionnaires, some patients queried the need to answer the same question again. Furthermore, the response options are different (Sk-16: Likert scale with options from 0 to 6; Sk-17: response options of never, rarely, sometimes, often, and all the time), and some participants reported more ease in responding to the Sk-17 options. This difference was observed by the authors during the research but not measured. 
The frequency of each response for each item of the instruments was studied to detect ground effects. Ground effects were found in Sk-17 (12 items), the DLQI-BRA (eight items), and Sk-16 (four items).

The results indicated adequate test-retest reproducibility (Table 5) for all instruments $($ ICC >0.80). Responsiveness analysis was also satisfactory for all dimensions $(p<0.05)$.

Table 5

Medians (p25-p75) of the instruments' dimension scores according to their test-retest reliability $(n=21)$ and responsiveness $(n=21)$.

\begin{tabular}{|lllll|}
\hline TEST-RETEST & Dimension & Score before & Score after & ICC (Cl 95\%) \\
\hline DLQI-BRA & & $4(1-11)$ & $4(1-10)$ & $0,97(0,93-0,99)$ \\
\hline Skindex-16 & Symptoms & $8(0-58)$ & $8(0-58)$ & $0,96(0,92-0,99)$ \\
\hline & Emoctions & $52(26-79)$ & $52(17-79)$ & $0,96(0,91-0,98)$ \\
\hline Skindex-17 & Functioning & $17(0-30)$ & $10(3-27)$ & $0,91(0,78-0,96)$ \\
\hline Symptoms & $2(1-6)$ & $4(1-7)$ & $0,87(0,52-0,97)$ \\
\hline DLQI-BRA & Psychosocial & $4(2-10)$ & $3(1-6)$ & $0,91(0,77-0,96)$ \\
\hline Skindex-16 & Dimension & Worse score & Better score & $\mathbf{p}^{*}$ \\
\hline & Symptoms & $67(27-87)$ & $21(6-54)$ & $<0,01$ \\
\hline Skindex-17 & Emoctions & $57(49-86)$ & $29(12-58)$ & $<0,01$ \\
\hline & Functioning & $53(22-78)$ & $23(3-43)$ & $<0,01$ \\
\hline *Wilcoxon test & Psychosocial & $10(3-16)$ & $5(1-10)$ & $<0,01$ \\
\hline
\end{tabular}

The TRI analysis of the instruments (Tables 6, 7, and 8) found adequate ordering for all items of the DLQIBRA, Sk-16, and Sk-17. All the items of the three instruments studied demonstrated adequate discrimination $(a>1)$. Four items of Sk-16 evidenced insufficient adjustment to the IRT model $(p<0.01)$; however, all the items of Sk-17 fit the model.

The items with the greatest discrimination were q3 (shopping/domestic activities) and q5 (social/leisure activities) in the DLQI; F2 (desire to be with people) and E6 (annoyance) in Sk-16; and S4 (irritated skin), P5 (closeness with loved ones), and P6 (doing things alone) in Sk-17. 
Notably, in the DLQI-BRA, q1 (symptoms) and q2 (embarrassment) were the items that identified the mildest impacts on HRQOL, while q6 (sport), q8 (partner/family member problems), q9 (sexual life), and q10 (treatment) were only sensitive to situations with more evident impacts. The Sk-16 and Sk-17 instruments more thoroughly assessed the different levels of impact on HRQOL. In Sk-16, items E1 (persistence/recurrence) and E2 (worry about skin condition) identified earlier impacts on HRQOL; item F3 (difficulty showing affection) was sensitive to more impactful situations. In Sk-17, items S4 (irritated skin) and P8 (embarrassment) indicated early impacts on HRQOL, and items P5 (closeness with loved ones) and P12 (sex life) delineated more substantial impacts on HRQOL.

Table 6

TRI parameters of the DLQI instrument $(n=229)$.

\begin{tabular}{|llllll|}
\hline Item & $\mathbf{a}$ & $\mathbf{b 1}$ & $\mathbf{b 2}$ & $\mathbf{b 3}$ & $\mathbf{p}$ \\
\hline q1 & 1,30 & $-0,67$ & 0,66 & 1,89 & 0,15 \\
\hline q2 & 1,14 & $-0,56$ & 0,66 & 1,83 & 0,66 \\
\hline q3 & 3,55 & 0,26 & 0,92 & 1,41 & 0,38 \\
\hline q4 & 1,52 & 0,21 & 0,86 & 1,56 & 0,37 \\
\hline q5 & 3,14 & 0,29 & 0,92 & 1,65 & 0,04 \\
\hline q6 & 1,40 & 1,12 & 1,79 & 2,61 & 0,50 \\
\hline q7 & 1,78 & 0,73 & 1,08 & 1,24 & 0,20 \\
\hline q8 & 2,05 & 1,17 & 1,94 & 2,44 & 0,16 \\
\hline q9 & 2,22 & 1,13 & 1,62 & 2,30 & 0,50 \\
\hline q10 & 1,15 & 1,04 & 2,38 & 3,17 & 0,83 \\
\hline (AIC = 4753,70; BIC = 4897,78; G2 = 2085,7, p = 0,999).
\end{tabular}


Table 7

TRI parameters of the Skindex-16 instrument $(n=229)$.

\begin{tabular}{|lllllllllll|}
\hline Item & $\mathbf{a 1}$ & $\mathbf{a} 2$ & $\mathbf{a 3}$ & $\mathbf{b 1}$ & $\mathbf{b 2}$ & $\mathbf{b 3}$ & $\mathbf{b 4}$ & $\mathbf{b 5}$ & $\mathbf{b 6}$ & $\mathbf{p}$ \\
\hline S1 & 1,88 & - & - & $-0,44$ & $-0,10$ & 0,30 & 0,72 & 1,20 & 1,58 & 0,10 \\
\hline S2 & 2,80 & - & - & 0,01 & 0,18 & 0,47 & 0,89 & 1,28 & 1,73 & $<0,01$ \\
\hline S3 & 2,16 & - & - & 0,24 & 0,46 & 0,72 & 1,08 & 1,46 & 1,79 & 0,16 \\
\hline S4 & 2,11 & - & - & $-0,68$ & $-0,31$ & $-0,01$ & 0,35 & 0,76 & 1,22 & 0,32 \\
\hline E1 & - & 1,95 & - & $-1,51$ & $-1,14$ & $-0,80$ & $-0,46$ & 0,03 & 0,46 & 0,05 \\
\hline E2 & - & 2,22 & - & $-1,48$ & $-1,16$ & $-0,88$ & $-0,53$ & $-0,11$ & 0,34 & 0,32 \\
\hline E3 & - & 2,76 & - & $-1,01$ & $-0,68$ & $-0,45$ & $-0,13$ & 0,22 & 0,54 & 0,13 \\
\hline E4 & - & 3,78 & - & $-0,75$ & $-0,49$ & $-0,26$ & 0,08 & 0,36 & 0,72 & 0,10 \\
\hline E5 & - & 3,19 & - & $-0,50$ & $-0,29$ & $-0,12$ & 0,16 & 0,47 & 0,79 & $<0,01$ \\
\hline E6 & - & 4,45 & - & $-0,77$ & $-0,43$ & $-0,22$ & 0,02 & 0,31 & 0,86 & 0,07 \\
\hline E7 & - & 3,55 & - & $-0,60$ & $-0,28$ & 0,02 & 0,29 & 0,60 & 0,87 & 0,05 \\
\hline F1 & - & - & 3,33 & $-0,03$ & 0,17 & 0,34 & 0,58 & 0,96 & 1,09 & 0,02 \\
\hline F2 & - & - & 5,39 & 0,12 & 0,28 & 0,40 & 0,62 & 0,91 & 1,07 & $<0,01$ \\
\hline F3 & - & - & 3,38 & 0,41 & 0,56 & 0,68 & 0,86 & 1,10 & 1,30 & $<0,01$ \\
\hline F4 & - & - & 2,63 & $-0,01$ & 0,12 & 0,33 & 0,58 & 0,79 & 1,02 & 0,06 \\
\hline F5 & - & - & 2,40 & $-0,10$ & 0,02 & 0,33 & 0,53 & 0,66 & 0,90 & 0,02 \\
\hline AIC = 12021,83;BIC $=12436,08 ; G 2=$ & $-5895,92, p=0,999)$. & & & \\
\hline
\end{tabular}


Table 8

TRI parameters of the Skindex-17 instrument $(n=229)$.

\begin{tabular}{|llllllll|}
\hline Item & a1 & a2 & b1 & b2 & b3 & b4 & p \\
\hline S1 & 2,37 & - & 0,12 & 0,44 & 1,15 & 1,91 & 0,01 \\
\hline S2 & 2,09 & - & $-0,49$ & 0,00 & 0,77 & 1,64 & 0,06 \\
\hline S3 & 1,84 & - & 0,36 & 0,81 & 1,49 & 2,28 & 0,01 \\
\hline S4 & 3,16 & - & $-0,80$ & $-0,22$ & 0,35 & 1,04 & 0,05 \\
\hline S5 & 1,57 & - & 0,03 & 1,07 & 2,05 & 3,29 & 0,26 \\
\hline P1 & - & 2,16 & $-0,23$ & 0,28 & 1,06 & 1,68 & 0,12 \\
\hline P2 & - & 3,18 & 0,47 & 0,89 & 1,49 & 2,12 & 0,70 \\
\hline P3 & - & 2,36 & 0,03 & 0,54 & 1,13 & 1,85 & 0,23 \\
\hline P4 & - & 1,91 & 0,20 & 0,63 & 1,12 & 2,00 & 0,09 \\
\hline P5 & - & 3,43 & 0,81 & 1,17 & 1,90 & 2,50 & 0,30 \\
\hline P6 & - & 3,38 & 0,74 & 1,10 & 1,58 & 2,07 & 0,43 \\
\hline P7 & - & 2,69 & 0,76 & 1,10 & 1,71 & 2,23 & 0,60 \\
\hline P8 & & 1,78 & $-0,97$ & $-0,31$ & 0,58 & 1,35 & 0,04 \\
\hline P9 & - & 2,20 & $-0,61$ & $-0,19$ & 0,61 & 1,25 & 0,05 \\
\hline P10 & - & 3,06 & 0,38 & 0,68 & 1,32 & 1,81 & 0,06 \\
\hline P11 & - & 2,63 & 0,60 & 0,87 & 1,34 & 1,97 & 0,08 \\
\hline P12 & - & 2,27 & 1,00 & 1,37 & 1,78 & 2,35 & 0,31 \\
\hline AIC= 9517; BIC= 9824; G2 = 6418, p = 0,999). & & \\
\hline
\end{tabular}

\section{Discussion}

Health-related quality of life is a subjective concept, and skin diseases can affect different dimensions of an individual's life. This study included patients with the most prevalent dermatoses in Brazil, according to a recent survey by the Brazilian Society of Dermatology that evaluated 9,629 dermatological consultations. (26) The predominance of women in this study is congruent with the pattern of dermatological care in Brazil, according to the same survey. The predominantly mild to moderate impact on HRQOL is common in dermatological series and requires instruments with sufficient discrimination in this impact range. $(4,11,27-33)$

The three instruments studied demonstrated adequate feasibility, internal consistencies, temporal stability, and sensitivity to change. The Sk-17 subscale of symptoms exhibited small psychometric 
indicators. Notably, the article describing Sk-17 (18) suggests that this domain has an interpretation of its dichotomized score - greater than or equal to five $x$ less than five. Thus, the non-continuous interpretation of this dimension may have decreased its accuracy. Over time, the emotions dimension of Sk-16 and psychosocial dimension of Sk-17 exhibited greater internal consistency than the DLQI-BRA, resulting in better discriminating power.

The DLQI is the most widely used HRQOL assessment tool in dermatology worldwide, and it correlated strongly with the Sk-17 domains ( $r h o \geq 0.75$ ). The $S k-16$ domains evidenced less expressive correlation (rho $\geq 0.59$ ).

While analyses of the ground effect of instruments are not always described in validation studies, they can influence the performance of the questionnaires. There was a significant number of items with a ground effect in the Sk-17 and DLQI questionnaires. The inclusion of dermatoses with mild to moderate HRQOL involvement favors the selection of options with lower scores, especially when the questionnaires use fewer than seven options per item. Notably, in the DLQI, two options (not relevant and not at all) that result in a score of zero can have markedly different practical implications. $(34,35)$

There is a tendency to use numerical scales $(0-10)$ in the construction of psychometric instruments. This affects internal consistency and dilutes the ground effect. However, the preference for answering questions using the numerical scale in Sk-17 rather than the Likert scale in Sk-16 reported by some patients indicates greater ease in considering concrete and non-numeric concepts when assessing quality of life.

The IRT analysis allowed a more detailed evaluation of the behavior of the items and instruments independently. In general, the items exhibited high discriminatory capacity; however, Sk-16 and Sk-17 presented items that more adequately represented mild impacts on HRQOL $(b<-1.00)$, while the DLQI presented items that resulted in $b>-0.50$, which can compromise sensitivity at lower scores. In addition, multidimensional instruments favor separate analyses of the disease's impact dimensions, allowing a detailed assessment of the type of impairment inflicted. (36)

This study has limitations related to the sample of patients from a single Brazilian center that is part of a public institution. These limitations, however, did not compromise the sample's representativeness regarding gender, age, education, income, and impact on HRQOL. Generic HRQOL instruments are fundamentally influenced by the type of disease and may not be suitable for comparing different disease groups $(14,37-39)$; however, this study used a parallel comparison of the diseases for the three instruments simultaneously.

Finally, this study contrasted the popularity, agility, clarity, and availability of the DLQI-BRA with the multidimensional analysis and greater discriminatory sensitivity to HRQOL in low Sk-16 and Sk-17 scores. Still, the performance of the multidimensional instruments, Sk-16 and Sk-17, was similar. The Sk17 performance correlated more strongly with the established DLQI-BRA. In addition, the greater ease in 
understanding the response options, as reported by the participants, and the well-established categorization of the Sk-17 scores are favorable points for its use.

These results provide researchers with support for the selection of the instrument in clinical trials and its interpretation, as well as for the development of new questionnaires.

\section{Conclusions}

The DLQI-BRA and the Brazilian versions of Sk-16 and Sk-17 demonstrated adequate psychometric performance for the assessment of HRQOL in a Brazilian sample. The multidimensional instruments (Sk16 and Sk-17) allowed a more detailed assessment of the impact on HRQOL and were more sensitive to mild impacts on patients' quality of life, especially regarding the emotional and psychosocial aspects.

\section{Abbreviations}

AIC - Akaike information criterion

BIC - Bayesian information criterion

$\mathrm{Cl}$ - Confidence Interval

DLQI - Dermatology Life Quality Index

DLQI-BRA - DLQI for the Portuguese language in Brazil

HRQOL - Health-related quality of life

ICC- Intraclass Correlation Coefficient

IRT - Item response theory

Sk-16 - Skindex-16

Sk-17 - Skindex-17

\section{Declarations}

Ethics approval and consent to participate: The study were in accordance with the ethical standards of the institutional research committee and with the 1964 Helsinki declaration and its later amendments or comparable ethical standards. The study was approved by their respective IRBs. Informed consent was obtained from all individual participants included in the study.

Consent for publication: Not applicable. 
Availability of data and materials: The datasets used and/or analysed during the current study are available from the corresponding author on reasonable request.

Competing interests: The authors declare that they have no competing interests.

Funding: Not applicable.

Authors' contributions: All authors contributed to the conception and designed of this paper and collected the data. M.F.S.J and H.A.M. wrote the paper; H.A.M. performed the analysis. All authors revised critically the work and reviewed the final version of the article. All authors agree to be accountable for all aspects of this study.

Acknowledgements: Not applicable.

\section{References}

1. Seidl EMF, Zannon CML da C. Qualidade de vida e saúde: aspectos conceituais e metodológicos. Cad Saude Publica [Internet]. 2004 Apr [cited 2019 Jan 9];20(2):580-8. Available from:

http://www.scielo.br/scielo.php?script=sci_arttext\&pid=S0102-311X2004000200027\&lng=pt\&tlng=pt

2. Finlay AY, Khan GK. Dermatology Life Quality Index (DLQI)-a simple practical measure for routine clinical use. Clin Exp Dermatol [Internet]. 1994 May [cited 2018 May 26];19(3):210-6. Available from: http://www.ncbi.nlm.nih.gov/pubmed/8033378

3. Martins GA, Arruda L, Mugnaini ASB. Validação de questionários de avaliação da qualidade de vida em pacientes de psoríase. An Bras Dermatol [Internet]. 2004 Oct [cited 2019 Feb 6];79(5):521-35. Available from: http://www.scielo.br/scielo.php?script=sci_arttext\&pid=S036505962004000500002\&lng=pt\&tlng=pt

4. Jorge MFS, Sousa TD, Pollo CF, Paiva BSR, lanhez M, Boza JC, et al. Dimensionality and psychometric analysis of DLQI in a Brazilian population. Health Qual Life Outcomes [Internet]. 2020 Aug 5 [cited 2021 Feb 22];18(1). Available from: https://pubmed.ncbi.nlm.nih.gov/32758227/

5. Lewis V, Finlay AY. 10 years experience of the Dermatology Life Quality Index (DLQI). J Investig dermatology Symp Proc [Internet]. 2004 Mar [cited 2018 May 26];9(2):169-80. Available from: http://linkinghub.elsevier.com/retrieve/pii/S0022202X15530054

6. Hongbo Y, Thomas CL, Harrison MA, Salek MS, Finlay AY. Translating the science of quality of life into practice: What do dermatology life quality index scores mean? J Invest Dermatol [Internet]. 2005 Oct [cited 2019 Jan 19];125(4):659-64. Available from:

http://linkinghub.elsevier.com/retrieve/pii/S0022202X15324957

7. Sánchez J, Zakzuk J, Cardona R. Evaluation of a Guidelines-Based Approach to the Treatment of Chronic Spontaneous Urticaria. J Allergy Clin Immunol Pract [Internet]. 2018 Jan [cited 2018 May 26];6(1):177-182.e1. Available from: http://linkinghub.elsevier.com/retrieve/pii/S2213219817304257 
8. Baker C, Mack A, Cooper A, Fischer G, Shumack S, Sidhu S, et al. Treatment goals for moderate to severe psoriasis: An Australian consensus. Australas J Dermatol [Internet]. 2013 May [cited 2018 May 26];54(2):148-54. Available from: http://www.ncbi.nlm.nih.gov/pubmed/23330815

9. Chernyshov P V, Tomas-Aragones L, Manolache L, Svensson A, Marron SE, Evers AWM, et al. Which acne treatment has the best influence on health-related quality of life? Literature review by the European Academy of Dermatology and Venereology Task Force on Quality of Life and Patient Oriented Outcomes. J Eur Acad Dermatology Venereol [Internet]. 2018 May 5 [cited 2018 May 25]; Available from: http://doi.wiley.com/10.1111/jdv.15048

10. Poór AK, Brodszky V, Péntek M, Gulácsi L, Ruzsa G, Hidvégi B, et al. Is the DLQI appropriate for medical decision-making in psoriasis patients? Arch Dermatol Res [Internet]. 2018 Jan 11 [cited 2019 Feb 17];310(1):47-55. Available from: http://link.springer.com/10.1007/s00403-017-1794-4

11. Twiss J, Meads DM, Preston EP, Crawford SR, McKenna SP. Can We Rely on the Dermatology Life Quality Index as a Measure of the Impact of Psoriasis or Atopic Dermatitis? J Invest Dermatol [Internet]. 2012 Jan [cited 2018 May 26];132(1):76-84. Available from: http://linkinghub.elsevier.com/retrieve/pii/S0022202X15354403

12. Viola K, Nijsten T, Krishnamurthy K. \&quot;Validation\&quot; of Outcome Measures in Dermatology. J Invest Dermatol [Internet]. 2013 [cited 2019 Jan 19];133. Available from: www.jidonline.org

13. Nijsten T, Meads DM, de Korte J, Sampogna F, Gelfand JM, Ongenae K, et al. Cross-Cultural Inequivalence of Dermatology-Specific Health-Related Quality of Life Instruments in Psoriasis Patients. J Invest Dermatol [Internet]. 2007 Oct [cited 2018 May 26];127(10):2315-22. Available from: http://linkinghub.elsevier.com/retrieve/pii/S0022202X15331353

14. Nijsten T, Meads DM, McKenna SP. Dimensionality of the dermatology life quality index (DLQI): a commentary. Acta Derm Venereol [Internet]. 2006 [cited 2019 Jan 19];86(3):284-5; author reply 2856. Available from: https://www.medicaljournals.se/acta/content/abstract/10.2340/00015555-0075

15. Chren MM, Lasek RJ, Quinn LM, Mostow EN, Zyzanski SJ. Skindex, a quality-of-life measure for patients with skin disease: reliability, validity, and responsiveness. J Invest Dermatol [Internet]. 1996 Nov [cited 2019 Feb 13];107(5):707-13. Available from:

http://www.ncbi.nlm.nih.gov/pubmed/8875954

16. Chren MM, Lasek RJ, Quinn LM, Covinsky KE. Convergent and discriminant validity of a generic and a disease-specific instrument to measure quality of life in patients with skin disease. J Invest Dermatol [Internet]. 1997 Jan [cited 2019 Jan 9];108(1):103-7. Available from: http://www.ncbi.nlm.nih.gov/pubmed/8980297

17. Chren MM, Lasek RJ, Sahay AP, Sands LP. Measurement properties of Skindex-16: a brief quality-oflife measure for patients with skin diseases. J Cutan Med Surg [Internet]. 2001 Mar 5 [cited 2018 May 26];5(2):105-10. Available from:

http://journals.sagepub.com/doi/10.1177/120347540100500202

18. Nijsten TEC, Sampogna F, Chren M-M, Abeni DD. Testing and Reducing Skindex-29 Using Rasch Analysis: Skindex-17. J Invest Dermatol [Internet]. 2006 Jun [cited 2018 May 26];126(6):1244-50. 
Available from: http://linkinghub.elsevier.com/retrieve/pii/S0022202X15329298

19. Jorge MFS, Mourão IB, Pollo CF, Sousa TD de, Meneguin S, Miot HA. Validation of the Skindex-17 quality of life assessment instrument for a Brazilian population. An Bras Dermatol [Internet]. 2021 Jan 1 [cited 2021 Feb 22];96(1):51-8. Available from: https://pubmed.ncbi.nlm.nih.gov/33281012/

20. Hutz, Claudio S.; Bandeira, DR (Org.); Trentini C (Org. ). Psicometria. 1st ed. Vol. 1. Porto alegre: ArtMed; 2015. 192 p.

21. Miot HA. Correlation analysis in clinical and experimental studies Análise de correlação em estudos clínicos e experimentais. Out-Dez [Internet]. 2018 [cited 2019 Jan 30];17(4):275-9. Available from: https://doi.org/10.1590/1677-5449.174118

22. Miot HA. Análise de concordância em estudos clínicos e experimentais. J Vasc Bras [Internet]. 2016 Jun [cited 2019 Jan 30];15(2):89-92. Available from:

http://www.ncbi.nlm.nih.gov/pubmed/29930571

23. Chalmers R. mirt: A Multidimensional Item Response Theory Package for the R Environment. J Stat Softw. 2012;48(6):1-29.

24. MacCalum R, Widaman K, Zhang S, Hong S. Sample size in factor analysis. Psychol Methods. 1999;4(1):84-99.

25. Kyriazos T. Applied Psychometrics: Sample Size and Sample Power Considerations in Factor Analysis (EFA, CFA) and SEM in General. Psychology. 2018;9(8):2207-30.

26. Sociedade Brasileira de Dermatologia HA, Miot HA, Penna G de O, Ramos AMC, Penna MLF, Schmidt SM, et al. Profile of dermatological consultations in Brazil (2018). An Bras Dermatol [Internet]. 2018 Dec [cited 2019 Mar 9];93(6):916-28. Available from: http://www.scielo.br/scielo.php? script=sci_arttext\&pid=S0365-05962018000600916\&lng=en\&tlng=en

27. da Silva MFP, Fortes MRP, Miot LDB, Marques SA. Psoríase: Correlação entre gravidade clínica (PASI) e qualidade de vida (DLQI) em pacientes avaliados antes e depois de tratamento sistêmico. An Bras Dermatol [Internet]. 2013 Sep [cited 2021 Feb 22];88(5):760-3. Available from: /pmc/articles/PMC3798353/

28. Tavora IG, Bissoli GC, Miot HA, Schmitt JV. Clinical manifestations and quality of life in hidradenitis suppurativa patients: survey of participants from an internet support group. An Bras Dermatol [Internet]. 2019 May 1 [cited 2021 Feb 22];94(3):298-303. Available from: http://dx.doi.org/10.1590/abd1806-4841.20197687

29. Camargo CC de, D'Elia MPB, Miot HA. Quality of life in men diagnosed with anogenital warts. An bras dermatol [Internet]. 2017 [cited 2021 Feb 22];427-9. Available from: http://www.scielo.br/scielo.php? script=sci_arttext\&pid=S0365-05962017000300427

30. Pollo CF, Miot LDB, Meneguin S, Miot HA. Development and validation of a multidimensional questionnaire for evaluating quality of life in melasma (HRQ-melasma). An Bras Dermatol [Internet]. 2018 Jun [cited 2019 Jan 19];93(3):391-6. Available from: http://www.ncbi.nlm.nih.gov/pubmed/29924234 
31. De Pinho Pimenta Borges A, Pelafsky VPC, Miot LDB, Miot HA. Quality of life with ingrown toenails: A cross-sectional study [Internet]. Vol. 43, Dermatologic Surgery. Lippincott Williams and Wilkins; 2017 [cited 2021 Feb 22]. p. 751-3. Available from: https://pubmed.ncbi.nlm.nih.gov/28291066/

32. Scotton MF, Miot HA, Abbade LPF. Factors that influence healing of chronic venous leg ulcers: A retrospective cohort. An Bras Dermatol [Internet]. 2014 [cited 2021 Feb 22];89(3):414-22. Available from: http://dx.doi.org/10.1590/abd1806-4841.20142687

33. Cavariani Silvares MR, Parise Fortes MR, Miot HA. Qualidade de vida em urticária crônica: inquérito em ambulatório público universitário, Botucatu (Brasil). Rev Assoc Med Bras [Internet]. 2011 Sep [cited 2021 Feb 22];57(5):577-82. Available from: https://pubmed.ncbi.nlm.nih.gov/22012294/

34. Rencz F, Poór AK, Péntek M, Holló P, Kárpáti S, Gulácsi L, et al. A detailed analysis of 'not relevant' responses on the DLQI in psoriasis: potential biases in treatment decisions. J Eur Acad Dermatology Venereol [Internet]. 2018 May [cited 2018 May 26];32(5):783-90. Available from: http://doi.wiley.com/10.1111/jdv.14676

35. Barbieri JS, Gelfand JM. Influence of "Not Relevant" Responses on the Dermatology Life Quality Index (DLQI) for Patients With Psoriasis in the United States. JAMA Dermatology [Internet]. 2019 Jun 1 [cited 2019 Jun 21];155(6):743.Availablefrom:http://archderm.jamanetwork.com/article.aspx? doi $=10.1001 /$ jamadermatol.2018.5655

36. Nijsten T. Dermatology life quality index: time to move forward. J Invest Dermatol [Internet]. 2012 Jan [cited 2019 Jan 19];132(1):11-3. Available from: https://linkinghub.elsevier.com/retrieve/pii/S0022202X15354579

37. He Z, Lo Martire R, Lu C, Liu H, Ma L, Huang Y, et al. Rasch Analysis of the Dermatology Life Quality Index Reveals Limited Application to Chinese Patients with Skin Disease. Acta Derm Venereol [Internet]. 2018 Jan 12 [cited 2019 Jan 19];98(1):59-64. Available from: http://www.medicaljournals.se/acta/content/abstract/10.2340/00015555-2742

38. Liu Y, Li T, An J, Zeng W, Xiao S. Rasch analysis holds no brief for the use of the Dermatology Life Quality Index (DLQI) in Chinese neurodermatitis patients. Health Qual Life Outcomes [Internet]. 2016 Dec 3 [cited 2018 May 25];14(1):17. Available from: http://hqlo.biomedcentral.com/articles/10.1186/s12955-016-0419-5

39. Ofenloch R, Diepgen T, Weisshaar E, Elsner P, Apfelbacher C. Assessing Health-related Quality of Life in Hand Eczema Patients: How to Overcome Psychometric Faults when Using the Dermatology Life Quality Index. Acta Derm Venereol [Internet]. 2014 [cited 2018 May 26];94(6):658-62. Available from: http://www.medicaljournals.se/acta/content/?doi=10.2340/00015555-1842 